\title{
Cultivation of Global Foreign Language Talents in Guangdong Applied Colleges Under The Background Of Great Bay Area of Guangdong Hongkong \& Macao
}

\author{
Aihua Zhu', a, Jiayi Zhong ${ }^{2, b}$ \\ ${ }^{1}$ Foreign Language Department of Guangzhou College of Technology and Business, \\ Guangzhou, China \\ 2 Economic Management Department of Guangzhou College of Technology and Business, \\ Guangzhou, China \\ aemail: 52597730@qq.com, bemail: 281099022@qq.com
}

Key words: global foreign language talents Cultural soft power Guangfu Culture

\begin{abstract}
Global foreign language talents are an upgraded version of compound foreign language talents. Foreign language education focuses on the cultivation of global talents in recent years. The core of their contents are national standpoint, world vision, innovative thinking, and multiple abilities. The Great Bay Area of Guangdong, Hong Kong\& Macao docked the "Belt and Road", with Hong Kong and Macao playing the role of connection, Communicating with people along the area. As an important base for international talent training, colleges and universities should integrate local culture into the cultivation of international foreign language talents with national sentiments, local culture and innovative thinking, provide endogenous motivation for economic construction, and promote talents for national cultural soft power.
\end{abstract}

\section{粤港澳大湾区背景下广东地方高校国际化外语人才培养策略研究 祝爱华1, a 钟嘉毅2,b \\ 1 广州工商学院外语系, 广州, 广东, 中国 \\ 2 广州工商学院经贸系, 广州, 广东, 中国 \\ aemail: 52597730@qq.com, bemail: 281099022@qq.com}

关键词：国际化外语人才 文化软实力 广府文化

摘要: 国际化外语人才是复合型外语人才的升级版, 也是近年来外语教育研究创新点, 其 内涵核心是民族立场、世界眼光，创新思维，多种能力。粤港澳大湾区对接“一带一路”, 发挥香港澳门的纽带作用, 创新经济, 推动文化互通, 人心相通。高校作为国际人才培养 的重要基地, 从本土文化着手, 培养具有民族情怀, 民族文化定力, 创新思维的国际化外 语人才, 为经济建设提供内生动力, 为国家文化软实力提升孕育人才。

\section{1. 引言}

外语教育界一直在实践中思考探索外语人才培养的相关问题（曹德明 2011; 戴炜栋,

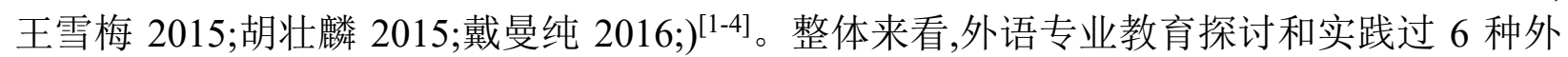
语人才培养模式，分别是“外语+专业方向”、“外语 专业知识”、“外语 专业”、“专业外语”、 “双学位”、“其他语种 英语”。前 4 种模式是一般较为通行的外语人才培养模式, 它们的共 性是“外语+专业”, 可能的差异则是各个高校在外语与专业的配置比例上有所不同, 后面是 
双语种 ${ }^{[5]}$ 。近年来, 关于国际化人才外语人才培养成为教学与创新点, 曹德明针对外语院 校培养的国际化人才提出了特质 6 个, 并提出在一系列对策 ${ }^{[6]}$; 仲伟合 (2015) 针对国际 化人才培养的基本内涵,提出在夯实学科专业的基础上全面培养学生的五种能力 ${ }^{[7]}$; 贾文键 Globalization 对此进行了具体分析, 并总结了北京外国语大学在培养民族立场、世界眼光 国际化外语人才上的经验 ${ }^{[8]}$; 李明秋（2016）指出国际化人才是在夯实外语学科专业基础 知识的基础上, 具备上述各种能力并能够经受多元文化的挑战和冲击, 以高瞻远瞩的视野与 包容的态度学习借鉴异域文化, 在做好国际化人才的同时深深根植于中华传统文化, 保持中 华民族的人格与国格 ${ }^{[9]}$; 王银泉 (2018) 提出融合型外语人才, 强调创新能力与全球化素 养, 大学不仅要服务国家创新驱动发展战略, 还要在此过程中实现教育理念和教学模式的 创新, 培养服务于国家战略, 中国文化“走出去”、促进“一带一路”建设和提升参与全球治理 能力的新型国际化人才[10]。

我们把国际化英语人才的核心内涵定位为: 外语能力、专业技能; 全球思维、创新思 维; 民族情怀与民族定力。民族情怀包括跨文化交际能力, 用外语介绍中国文化、传播中 国文化的能力。

\section{2.国际化外语人才培养对粤港澳大湾区建设的意义}

2017 年“粤港澳大湾区”正式写入中央政府工作报告, 这标志着建设世界级湾区正式上 升为国家战略。其所担负的战略使命是对标纽约、旧金山、东京三大湾区, 发展成为对世 界经济具有主导作用的大湾区。从国家层面提出“粤港澳大湾区”概念将推动粤港澳企业联 合“走出去”，成为“一带一路”的重要支撑节点。粤港澳大湾区建设另一使命是推动中国文 化与相关国家的人心相通, 文化互通。在这样一个开放的国际大湾区环境中, 外语已成为生 活的一部分,是“国际型” 区域人才必须掌握和利用的信息资源, 只有适应时代和社会需求培 养外语人才,才能体现外语在社会中的价值并充分发挥其作用。

\section{1 经济意义}

国际化外语人才培养是粤港澳大湾区战略规划的现实需要和重要保证, 也是提升大湾 区城市群发展创新的内生动力。人才战略是国家经济社会发展的一级战略, 人才竞争是城 市发展的核心构成要素,人才的质量代表着一个地区的综合实力和综合竞争力,也是城市群 发展的战略基石。粤港澳大湾区经济发展需要不断深化改革步伐培养国际化应用型人才作 为战略,才能从容应对经济发展带来的各种挑战和风险。充分释放外语人才的创造力和沟通 能力, 以人才战略为基础引领经济发展, 营造出良好的以人才为基础的社会发展氛围, 创造 出更多更有用的经济价值。

\section{2文化意义}

粤港澳大湾区最重要的特征是跨境整合 : 一个国家、两种制度、粤、港、澳三个地区、 三种语系, 四种不同语言, 以广府文化为主流文化。香港与总人口 20 亿的英联邦国家有传 统紧密关系, 是中国文化走出去的纽带。广东是最大的侨乡, 广府后裔华侨遍布全球, 广 府文化在全球华人文化中享有盛誉。在粤港澳大湾区建设中，国际化英语人才是对外交流 的桥梁, 也承载着中华文化尤其是广府文化海外传播的重担。培养人才与国际接轨, 是为了 搭起平等交流的渠道, 立足于本土、民族, 更好的传播中国声音, 讲好中国故事, 提升国 家文化软实力。

\section{3.广东地方高校国际化外语人才培养策略}

目前的外语教学体系中已经形成了完善的学科体系，但是外语人才培养的定位需与 时俱进, 为国家、地域经济文化发展服务, 外语建设为国家建设铺路。注重高等教育与 
经济社会的深度融合, 注重提升高等教育国际化水平。这是国外许多发达国家的做法。关 于国际化英语人才培养的研究不同的地方的大学有不同的做法。北京外国语大学的国际 化外语人才培养使之成为全国就业力最强的大学。学生到目的语国交流学习。在教学改 革中,北外在原有课程体系中增设院系平台课程和用对象国语言讲授的中国文化课程,以期 在提高学生中国文化素养的同时,使学生掌握“中国文化走出去”的理论和方法。

广州外语外贸大学在总结学校原有国际化人才培养强调“专业教学与外语教学融合”的 基础上，提出了关于拔尖创新型国际化人才培养的“三个深度融合”模式:坚持专业教学与外 语教学的深度融合; 推进理论教学与实践教学的深度融合; 强化本土教育与境外教育的 深度融合。

这些高校的做法为其他院校的国际化英语人才提供了借鉴经验。人才是经济与文化 发展的后劲与核心, 国际化外语人才核心内涵是语言加专业, 创新思维, 国际视野、本 土情怀。培养服务于粤港澳大湾区背景下广府文化传播的国际化英语人才是可以从以两 个方面来探讨。

\section{1 培养具有创新思维的复合型语言人才}

国际化外语人才必须有扎实的语言基本功, 否则一切都是无源之水无本之木。在经济 急速发展的时代, 社会对单纯语言人才的需求在下降, 因此, 外语人才还必须有一定的专 业知识, 熟悉国际事务国际规则, 能多角度解决问题, 具备三角矫正能力。广东地方高校 拥港抱湾, 具有天然的地理与传统优势, 培养适应地方经济发展的国际化外语人才可以从 以下几个方面进行尝试:

3.1.1.加强合作办学。

发挥广东地区地理优势与经济优势, 加强粤港澳三地高校合作交流, 推进中外高等教 育合作，加大校企合作力度，推动协同人才培养。

粤港澳地区教育资源丰厚，世界百强名校有 5 所，专门的外语外贸类院校 1 所，以及 特色华侨大学, 为大湾区内教育交流合作提供了现实可能; 广东省政府致力于引进世界知 名大学来粤合作举办独立设置高等学校, 如: 北京师范大学与香港浸会大学在珠海举办联 合国际学院后, 香港中文大学 (深圳) 、深圳北理莫斯科大学落户深圳, 广东以色列理工学院 落户汕头等; 加强校企合作, 实现订单式培养, 企业与人才精准对接, 避免人才与企业需 求两张皮局面。

3.1.2. 资源共享。

实现教育教学资源共享与人才资源共享。教学资源的来源既有境外高校，也有省内外 高校。设立专项经费, 构建常态化教学资源共享机制。每年固定引进境外高校专业课程的 教学视频、教学资料等, 作为本校课程建设的组成部分。

目前人才区域分布不平衡，香港、澳门，深圳、广州集中的人才优势大于其他地区， 重点高校集中的人才优于其他普通院校。人才共享是大湾区发展的迫切需求, 发挥人才最 大效用，必须建立人才共享机制。

3.1.3.构建多元化英语师资库。

国际化英语人才的培养对教师提出了提出了文化、语言、专业背景等方面的要求, 外 语教师不但要具备扎实的外语语言底蕴, 还要具备深厚的中国文化素养; 不仅要做语言的 解惑者, 更要成为文化之旅的引路人, 更要具备其他学科的专业素养。这是目前国际化外 语人才需要解决的一个重要问题, 在师资建设上应坚持引进与培养并进举措, 海外引进高 精尖人才，本土培养优秀人才，打破人才制约壁垒，不拘一格用人才。原则坚持“专、兼、 邀、聘”并举,建立由国内外专家学者、专业技术拔尖人才、企业经营管理人才和乡土人才 等构成的多元化外语培训师资库, 根据不同类型课程、不同的教学内容、不同的教学对象和 教学要求配备师资力量 ${ }^{[11]}$ 。

3.1.4. 实施学科融合、人才复合的培养模式 
复合型人才一定具备融合的知识和能力。社会对具备交叉学科知识体系的融合型外语 人才需求越来越大,未来的外语人才不但要掌握外语学科的核心知识, 而且要掌握相关学科 的知识,具备学科间的知识交叉和融合。认识、理解不同专业学科的特点, 有意识地综合各个 学科各个方法的优长, 在跨文化、跨学科背景下, 从多维思考的视角出发, 更好地解决同一个 问题。

\section{2突出办学地方特色, 开展广府文化特色课程教学, 培养民族情怀}

目前国际化人才培养大多止于语言能力的培养，在一定程度上掌握对象国文化、社会、 政治、经济等状况, 但是能从中国传统文化背景出发、从独特的区域文化出发、从当代中国 现实状况出发, 做出不同于其他文化背景的人的理解与判断的, 是软肋。地域文化是高等 学校实现办学特色的重要源泉, 也 是地方高校特色办学理念生成的基石。广东省地方高 校的生源主要来自本地, 其人才培养目标设定为服务于粤港澳大湾区建设。只有植根于地 域文化的沃土, 才能使培养出来的人才适应大湾区发展的需要。在粤港澳大湾区建设中, 将广府文化纳入国际化英语人才的培养体系, 不仅是出于补短板的考虑, 更是地方高校特 色办学的需求。培养具有民族立场世界眼光的外语人才可从以下几个方面进行

\subsection{1. 本土教材建设}

目前的教材普遍存在英美文化比例过大，本国文化偏小或者没有的问题，而地域特色 的文化几乎没有。要培养深深扎根于广府文化的国际化英语人才, 必须加大乡土教材、本 土文化译本建设。从广府文化品牌的外译入手, 高校可编写一本或一套中英文口袋书, 将 广府文化的历史、民俗、特产、旅游、传统医学（如陈李济、潘高寿）、等精心译成英语, 有条件的还可翻译一些地方史志、古籍, 以激活传统文化价值, 使其能古为今用提升中国 文化的吸引力和感召力。

\subsection{2. 广府特色选修课程设置}

开设广府文化英语选修课，建设广府特色课程平台，发挥校际合作，境内外合作，通 过慕课, 网络课程实现资源共享; 开设广府文化特色讲座, 从表层物质文化到深层的精神 文化解析广府文化。广东非遗文化多, 广东本土生源对当地文化比较了解, 通过英语选修 课程学习本地文化不仅可以提高学生的学习兴趣, 认识到这些特色文化是中华民族的精神 财富, 还可以感受到特色文化的鬼未和深厚内涵, 提高文化素养, 增强民族自信心和文化 责任感。

\subsection{3. 创新教学实训方法}

创新教育方式。加强教学改革力度, 强化思维训练, 培养创新人才。教学应激发学生 独立思考、大胆质疑, 追新求异, 多维度联想语言知识, 探求语言知识结构, 摸索语言学习 的有效路径; 激发创新思维, 鼓励创新, 培育创新素质。推进信息技术与外语教学深度融合, 善于运用丰富的在线教学和移动学习资源, 利用丰富的自媒体资源, 开设开放式课程, 翻 转课堂, MOOC 等开放式教学模式, 使教师授课与学生探究相得益彰, 课堂教学与课外网 络学习互为补充, 实现互动式、个性化的“教”与“学”, 落实创新型人才培养。

创新实训实践, 加大校企合作力度。发挥粤港澳地区企业众多优势, 秉承广府文化务 实精神, 培养实践能力出众语言精英人才。从行业和企业聘请创新创业导师, 实施校企合 作, 为学生提供更多创新实践机会; 促进学生开展创新创业实践; 推动大学科技园与高新 区共建外语领军人才载体, 支持产学研紧密合作, 提供国际化英语人才走向社会、走向国际 的锻炼机会。

3.2.4. 构建特色校园文化, 建设隐性课程。

开展各种具有地域特色的校园实践活动, 营造特色校园环境, 成立具有地域文化特色 的学生社团, 组织学生创作具有地方特色的作品, 并通过各类学生竞赛、文化节、艺术节 等活动进行展演, 激活传统广府文化。如: 龙舟说唱、广东醒狮、广东剪纸等都可以通过 各地方高校的校园实践活动进行传承和弘扬。还可通过校园社团加强与境外高校交流, 将 
凝练于校园文化中的广府文化辐射到地方。

加强各种媒体的宣传, 发挥微信, 公众号, 博客等自媒体的作用, 建设广府文化双语 网站、公众号, 制作广府文化英文介绍视频作为自媒体的学习的一个部分,

3.2.5. 构建科学评价机制。

从评价内容到评价主体都需顾及。评价内容应该将地方文化嵌入到英语课考核过程 中, 要求学生平时参与英语课堂涉及中外文化方面的讨论、回答问题和完成口头报告;课程 考查要涵盖本土文化内容, 若对学生没有一定形式的考核要求, 本土文化学习肯定会不了 了之。评价的主体应集学生个体、教师、学生集体、企业评价四个部分为一体, 进行综合 测评。

\section{4.结语}

国际化外语人才是对外交流的桥梁，粤港澳大湾区背景下积极发挥香港、澳门的纽带 作用, 对接英语葡语国家, 香港与总人口 20 亿的英联邦国家，如英国、印度、新加坡、马 来西亚、孟加拉国、巴基斯坦、斯里兰卡、南非、澳大利亚、新西兰、加拿大等有传统紧 密关系，澳门与葡语国家关系紧密。作为粤港澳三地共同的同宗同源的广府文化，如将其 人文自然资源进行深度挖掘、整合，融入到教育教学中，培养通晓广府文化具有世界眼光 的国际化外语人才，可提升民族情怀，提高跨文化交际能力，更好担当起文化传播的使命。 这对于讲好中国故事，传播中国声音有重要意义。但目前也遇到了一定的困难，如建材问 题，广府特色词汇翻译。此外国际化外语人才离不开科学、有效、规范的评估体系。评价 语言技能的各种专业考试如专八、专四已经成熟，但是如何评价国际化外语人才，新出台 的国才考试是参考的标杆。最后, 学科融合、复合型外语人才缺少后续培养机制。开设更 高学位教育的院校少, 人才培养后续动力不足。这些问题有待更深一步的探讨。

致谢:

本文是广州市哲学社会科学“十三五”规划 2018 年度课题（2018GZGJ148）阶段性成 果

\section{Reference:}

[1] Deming Cao, Reflections on the Cultivation of International Foreign Language Talents in Higher Foreign Language Institutions, Foreign Language Learning Theory and Practice, vol. 2011,(3):1-5.

[2] Weidong Dai;Xuemei Wang. The Developmental Strategies of the Discipline of Foreign Languages and Literature under the Background of Chinese Culture Diffusion, Journal of PLA University of Foreign Languages, 2015, 38(04): 1-11 159.

[3] Zhuanglin Hu, Several Viewpoints on Foreign Language Education Reform in China Foreign Language Education, vol 2015, (1) :52-55.

[4] Manchun Dai. Sample survey of foreign language talent demand in China, Foreign Language Teaching and Research, vol2016 (4): 614-624.

[5] Zhi Lu, Construction of an education model for innovative foreign language talents. Foreign, Language World.Vol2018(01):36-42.

[6] Deming Cao, On Talent Cultivation in Higher Education Institutions of Foreign Languages, Foreign Language Learning Theory and Practice, vol2011,(3):1-5.

[7] Wenjian Jia, The Connotation and Standards of International Talents Training in Foreign 
Language Majors_— The Concept and Practice of International Talents Training in Beijing Foreign Studies University China University Teaching,vol2015,(1):22-28

[8] Weihe Zhong, Top-notch Innovative International Talent Training: A Case Study from Guangdong University of Foreign Studies, Journal of Guangdong University of Foreign Studies, vol 2013,(1):98-101.

[9] Strategic research on accelerating the promotion of international application of foreign language talents in Dalian, Higher Agricultural Education,vol2016(01):21-24.

[10] Yinquan Wang, Towards the Cultivation of Innovation Competency and Global Literacy for China's Integrated Foreign Language Talents in Compliance with the National Strategies, Contemporary Foreign Languages Studies, vol2018(02):43-54 110

[11]JunWang;Jun Yuan, Construction Report on Guangdong, Hong Kong and Macao Great Bay area, Social Science Academic Press, Vol2018,p188,Guangzhou 